\title{
El trato preferencial a las fuentes
}

\section{gubernamentales: análisis crítico del discurso acerca de la migración venezolana, en los periódicos El Comercio y El Universo}

\section{Preferencial tretment of government sources: critical analysis of the discourse about Venezuelan migration in El Comercio and El Universo newspapers}

\author{
Hernán Pillajo Borja \\ Magister en Comunicación con mención en Opinión Pública. Desarrolló su actividad periodística profesional entre 1993 y 2011. En \\ 2016 fue docente de la Facultad de Ciencias de la Comunicación de la Universidad Laica Eloy Alfaro de Manabí. Actualmente es \\ profesor de Lenguaje y Comunicación de la Universidad Politécnica Estatal del Carchi.
}

Correo: patriciopillajoborja@gmail.com

\section{Resumen}

En las noticias difundidas por los periódicos El Comercio y El Universo acerca de la migración venezolana hacia el Ecuador, el relato del gobierno tuvo un trato privilegiado. El Análisis Crítico del Discurso muestra cómo dichos medios se identificaron con la perspectiva del poder político, que decretó varias acciones que fueron denunciadas como discriminatorias contra estos ciudadanos. Mediante la jerarquización, la inclusión y las omisiones, entre otros recursos usuales en la redacción informativa, los migrantes fueron mostrados como sujetos problemáticos de recepción y víctimas a la vez.

Palabras clave: análisis crítico del discurso, migración, venezolanos, periódicos, Ecuador.

\section{Abstract}

In the diffused news by the newspapers El Comercio and El Universo, about the venezuelan migration in Ecuador, the government's story had a privileged access. The Critical Discourse Analysis shows how these media were identified with the political power perspective, which decreed several actions that were denounced as discriminatory against these citizens. Through hierarchy, inclusion and omissions, among other usual resources in informative writing, migrants were shown as problematic subjects of reception and victims at the same time.

Keywords: critical analysis of discourse, migration, venezuelans, newspapers, Ecuador. 


\section{Introducción}

Los temas sobre emigración e inmigración han ocupado un importante espacio dentro del debate público en el Ecuador. Sin embargo, ambos procesos, que han incidido como en cualquier sociedad en la conformación poblacional, comportamiento, cultura e identidad de este país, han sido muchas veces estigmatizados mediante relatos cuya visibilidad ha dependido, sobre todo, de la circulación que les han brindado los diferentes medios de comunicación social.

La prensa ha reproducido ciertos discursos discriminatorios provenientes de sus audiencias. Así también ha elaborado sus propias representaciones y narrativas acerca de este lado de la realidad social, lo que devela tanto la concepción dominante acerca del otro como el pensamiento y valores personales (Retis, 2004).

Observemos el caso del colectivo de colombianos, el grupo más numeroso en el Ecuador, que llegó en 2010 a 135 mil personas en calidad de refugiadas (ACNUR, 2010, citado en Ospina y Ortega, 2012). Sobre ellos se creó una imagen de generadores de inseguridad, drogas y prostitución, alimentada, según Schussler (2009), por diversas fuentes, entre ellas gobernantes y medios, quienes los convirtieron en "chivos expiatorios por la violencia creciente y la falta de trabajo que han surgido como consecuencia de los ajustes neoliberales y la crisis financiera del 1999" (p. 52).

En el trabajo citado, el investigador se refiere a una nota publicada en 2006 por el diario La Hora en la que se establecía que el $76 \%$ de ecuatorianos rechazaba la presencia de la población inmigrante colombiana y el 35\% favorecía la deportación de indocumentados de ese país (p. 53).
Aunque se podría argumentar, a partir de las premisas periodísticas, que se trataba solo de un hecho noticiable más, la selección y publicación del informe dan pistas acerca del tipo de relato que favoreció este medio. Estas operaciones forman parte del proceso de construcción de la realidad presente en el discurso informativo.

Otro caso similar ocurrió con la población cubana, que en 2008 se convirtió en el quinto grupo de migrantes más numeroso dentro del Ecuador, con 6.617 personas (Flor, 2015). Su presencia motivó expresiones discriminatorias que se escucharon con fuerza en medio del debate sobre los derechos que les asistían a los extranjeros mediante la nueva Constitución, que incorporó el concepto de ciudadanía universal y libre movilidad.

La numerosa presencia de cubanos, junto con la aprobación de un decreto ejecutivo que permitía la entrada al país sin pasaporte, así como la animadversión que despertó en algunos sectores el gobierno de turno, fueron el escenario para expresiones xenófobas de quienes miraron a los cubanos como una nueva amenaza a su seguridad, tal como lo hicieron en su momento con los colombianos (Muñoz y Aguilar, 2014). Según estos autores, el tipo de tratamiento de la noticia sobre migración en los medios, sin que se ahondara en las causas sociales, políticas y culturales relacionadas con el fenómeno, acarreó el aumento de la percepción de inseguridad. No fue únicamente la prensa la que generó la sensación de amenaza ya que la respuesta del Estado ecuatoriano tuvo que ver más con acciones vinculadas a la securitización y a las regulaciones migratorias, antes que con la aplicación de los principios de ciudadanía universal vigentes en la nueva Carta Magna (Flor, 2015). 
La discriminación en contra de los extranjeros resulta paradójica en una sociedad como la ecuatoriana, que conoce de cerca las razones y consecuencias de la migración. De acuerdo con Graton (2005) esta puede dividirse en dos fases: de 1960 a 1995 y de 1995 hasta el 2004. Durante la primera, la movilización de ecuatorianos se dio preferentemente hacia los Estados Unidos, coincidentemente con el declive de las exportaciones del sombrero de paja toquilla o "Panama Hat" y se dio sobre todo entre oriundos de la provincia del Azuay. Así, en los años 90, la emigración neta - diferencia entre salidas y retornos - llegó a 30 mil personas por año hacia el país del norte (p. 34).

La crisis económica de 1998 - que provocó "el empobrecimiento más acelerado en la historia de América Latina con excepción de Argentina 2001" (ILDIS 2002 citado en Gratón 2005) - dio curso a la segunda fase migratoria de ecuatorianos, esta vez con rumbo hacia Europa, preferentemente hacia España. En el Censo Nacional del 2001 se determinó que 560 mil personas salieron del país hasta el año 2000 (p.38).

El impacto social de este último proceso migratorio tuvo repercusiones en todo nivel dentro del Ecuador y la prensa no estuvo al margen de su influencia, al punto que muchos periódicos llegaron a reconfigurar su estructura periodística, física y tecnológica para atender la demanda comunicacional que el éxodo provocó en la sociedad ecuatoriana (Cruz, 2009).

A partir del año 2001, los diarios de mayor circulación implementaron secciones específicas, suplementos y una serie de estrategias interactivas en la red para atender informativamente a los ecuatorianos en el exterior y a sus familiares que se quedaron en territorio nacional. Cruz agrega que:

El 2002 marcó una ruptura en los contenidos informativos sobre el fenómeno migratorio en los periódicos en papel y en los periódicos en línea. El Universo, el diario de la Costa con mayor circulación nacional, creó la sección "Migración" en la que se centralizan notas exclusivamente sobre el tema migratorio y que, en la página $w e b$ de ese periódico, permite el acceso al portal "Voz de los migrantes" desde donde los hombres y mujeres que han salido del país envían mensajes de texto a sus familiares y amigos que se quedaron (p.35).

Sin embargo, el interés evidenciado en los medios por la situación de los migrantes ecuatorianos adoptó formas simplistas, con estereotipos de victimización y espectacularización en el relato, con tonos negativos y hasta deshumanizados en sus titulares, particularmente cuando estos desplazamientos estuvieron marcados por la tragedia (Cerbino, Benalcázar y Pérez, 2006; Checa, 2007).

\section{Xenofobia contra los venezolanos}

Un situación parecida lo han vivido recientemente los migrantes venezolanos, cuyo número, hasta mediados del 2018, era incierto debido a que muchos solo estuvieron de paso hacia Perú y Chile ${ }^{1}$. Su presencia en el Ecuador se percibió con

\footnotetext{
1 El Alto Comisionado de las Naciones Unidas para los Refugiados ACNUR reportó el arribo de 547.140 venezolanos de enero a julio del 2018. La Cancillería de Ecuador, por su parte, dijo que se habían entregado 24. 616 visas de trabajo en ese mismo lapso y 23.059 el año anterior (El Comercio 12, 7, 2018).
} 
más fuerza a partir de julio del 2017, cuando las autoridades del control migratorio de Rumichaca, frontera con Colombia, informaron del arribo diario de 2 mil personas provenientes de ese país ( $E l$ Universo 28 de julio 2017).

A partir de este momento, en la prensa y en las charlas cotidianas el tema de los venezolanos cobró fuerza, más aún cuando se vieron relacionados con algunos sucesos que adquirieron el estatus de noticiables. Entre estos estuvo la viralización, en septiembre del 2017, de un video en el cual se le preguntó a una joven vendedora ambulante su opinión acerca del aspecto físico de los ecuatorianos. Su respuesta dio lugar a una proliferación de epítetos que la embajadora de Venezuela y los dirigentes de dicha colonia pidieron disculpas públicas por las declaraciones de su compatriota. En medio de esta polémica, una presentadora de noticias de farándula del canal Teleamazonas, comunicadora de igual origen, parodió el habla de las vendedoras de golosinas tradicionales, lo que avivó la difusión de mensajes en contra de los recién llegados (El Nacional 15 de septiembre 2017).

Otro caso tuvo lugar el 3 de mayo del 2018 en Ambato, ciudad ubicada en la sierra centro del Ecuador, cuando un taxista fue asesinado por un hombre que solo después de algunos días se comprobó que era de nacionalidad venezolana (Infobae 5 de mayo 2018). El violento suceso, que fue grabado por la cámara de vigilancia del vehículo y difundido por las redes sociales, provocó en la citada urbe manifestaciones públicas de condena a la presencia de este colectivo de extranjeros (La Hora 9 de mayo 2018).

No obstante, la declaración de emergencia migratoria efectuada por el gobierno ecuatoriano el 8 de agosto del
2018 para las provincias de Carchi, Pichincha y El Oro por la llegada diaria de 4.200 venezolanos (El Comercio $9 \mathrm{de}$ agosto 2018) y la decisión de exigirles pasaporte fueron los hechos que mayor cantidad de información y de opiniones generaron en los medios. Según el ministro del Interior, Mauro Toscanini, esta última medida, que entró en vigencia diez días después, respondía a la necesidad de organizarlos y a su vez calmar la xenofobia que su presencia había despertado tanto en las calles como en las redes sociales (El Comercio 19 de agosto 2018).

\section{El Análisis Crítico del Discurso Periodístico: li- neamientos metodológicos}

El Análisis Crítico del Discurso (ACD) es una perspectiva crítica que se centra en el papel que cumple el relato en el ejercicio abusivo del poder (van Djik, 2003). Bajo este enfoque, se considera al lenguaje como una práctica social y, en tal sentido, se observa la interacción dialéctica entre un discurso determinado y el contexto en el que se enmarca. Es dialéctica porque, tal como señalan Fairclough y Wodan (1996) "el suceso discursivo está moldeado por las situaciones, instituciones y estructuras sociales pero a su vez les da forma" (p.367).

La propia palabra discurso nos ubica en una forma de entender el lenguaje, no únicamente como sistema de signos abstractos sino inmersos en un complejo entorno psicológico, político, cultural, etc. Estos elementos nos muestran que no hay nada inocente en los signos, "que la connotación va con la denotación, que el lenguaje muestra, pero también distorsiona y oculta, que a veces lo expresado refleja directamente lo pen- 
sado y a veces sólo es un indicio ligero, sutil, cínico" (Santander, 2011, p. 208).

$\mathrm{Al}$ estudiar los vínculos entre lo textual y lo co-textual para denunciar la dominación que se ejerce mediante el discurso, el ACD reconoce y reivindica una postura ideológica, lo que no implica que carezca del rigor investigativo que poseen otros enfoques. Por su riqueza multidisciplinar, resulta difícil pensar en una metodología estandarizada para su aplicación, no obstante la naturaleza fundamentalmente verbal del discurso demanda, como paso primordial de cualquier ACD, la identificación y descripción de las diferentes formas gramaticales, así como pragmáticas, de interacción, estilísticas, retóricas, narrativas, etc., para relacionarlas dialécticamente con los diversos aspectos de orden social, político, cultural, cognitivo en los que se hallan inmersos y que nos permitan develar la ideología presente en los relatos (Fairclough y Wodan, 1996; van Djik, 2003; Retis, 2004).

Así, un ACD aplicado al discurso periodístico busca exponer los contenidos ideológicos subyacentes en las características textuales de este género discursivo reflejada en los antetítulos, títulos, subtítulos, tipografía, fotografía, cuerpo de la noticia o editorial, disposición espacial de las imágenes, cuadros y demás elementos semióticos o multimedia.

Adicionalmente, observa las diferentes estrategias retóricas de elaboración del relato noticioso como jerarquización de los acontecimientos, inclusiones, silencios, yuxtaposición de ideas, metonimia y otros recursos característicos de este discurso como la emotividad y el uso de estereotipos, usuales en la construcción de noticias, que son el espacio ideal para la producción y circulación de ideologías autoritarias que, como en el caso migratorio, encasillan la identidad propia y la del otro en determinados moldes. Como advierten Alsina y Gaya (2001), si los periodistas tienen que decir mucho en espacios y tiempos muy cortos, el recurso de empaquetar información en estereotipos, les permite hacerlo, pero a condición de distorsionar la comprensión que se tiene acerca de otras culturas.

A diferencia de otros discursos como el político o el publicitario, en los cuales la ideología partidista o de mercado es generalmente aceptada, en un buen sector del periodismo la negación de esta es reiterativa ya que reivindica una actividad apegada a la defensa de la democracia y la libertad, valores que no son considerados como ideológicos para la ortodoxia tradicional de modelo de prensa anglosajón (Espeche, 2010). Esta pretensión de objetividad, así como su función mediadora convierten a los medios en un lugar estratégico de constitución del discurso social, en la construcción simbólica de la realidad, la prensa se configura como el espacio más estructurado y coherente "de ahí el cometido del periódico como marcador de identidad" (Retis, 2004, p.25)

El corpus analizado en este trabajo se configuró a partir de la emergencia migratoria y la exigencia de pasaporte para el ingreso de los venezolanos al Ecuador. A partir de estos acontecimientos se incrementó significativamente en la prensa local el flujo de noticias acerca de este tema. Así, por ejemplo, entre 1 y el 30 de septiembre 2017, cuando circularon las expresiones xenófobas contra el citado colectivo por la difusión del video sobre el aspecto físico de los ecuatorianos, el buscador web de diario El Comercio registra 20 notas con la palabra "venezolanos", incluidas aquellas relacionadas con la situa- 
ción política de ese país. Con las fechas 1 al 31de agosto del 2018, días durante los cuales el gobierno de Lenín Moreno decretó las mencionadas medidas, el mismo buscador web contabiliza 183 entradas con este gentilicio.

Diario El Comercio de Quito junto con El Universo de Guayaquil son periódicos de circulación nacional y obtuvieron en 2015 las ponderaciones más altas de credibilidad a nivel de la prensa escrita en las tres principales ciudades del Ecuador: $39,6 \%$ y $29,7 \%$ respectivamente, de acuerdo con la investigación "Credibilidad de los medios, fuentes y periodistas en el Ecuador", realizada por la Universidad Los Hemisferios (Rodrigo, 2016).

\section{La imagen de los venezolanos en los periódi- cos El Comercio y El Universo}

En la páginados de la edición del jueves 9 de agosto de El Comercio de Quito, se puede apreciar una serie de enunciados que muestran a los migrantes venezolanos como sujetos problemáticos de recepción debido a:

1) El elevado número de migrantes que ingresan al Ecuador:

"Ella (Juldy Díaz) forma parte de los 4 mil venezolanos que están llegando en estos días, cifra que duplica el flujo normal según las autoridades".

2) Las malas condiciones de salud que presentan:

"También informó (Itamar Rodríguez viceministro de Atención Integral de Salud) que hay varias enfermedades registradas en los ciudadanos que ingresan al país. Entre las principales están las in- fecciones intestinales, deshidratación y rinitis. También hay males crónicos como la diabetes e hipertensión".

3) Los altos costos que su presencia le representan al Estado ecuatoriano: "El movimiento de personas y la alerta de la OMS impulsaron que salud aumente el presupuesto destinado para vacunas. Pasó de 13 millones a 18 millones. Se sumó una inversión de 4 millones más para la contratación de vacunadores entre mayo y junio".

La problemática de la recepción se generaliza a todos estos migrantes sin considerar, por ejemplo, las excepciones a las condiciones de salud y de pobreza extrema que pudieron presentarse entre los viajeros si se toma en cuenta, precisamente, la gran cantidad de personas que deseaban ingresar al país.

Esta representación nos conduce a la emotividad, "estrategia mediática de persuasión que apela a la dimensión emocional de aquello que es noticiable" (van Dijk, 1990, 126), con la que se enfoca el tema a partir de la declaración de emergencia migratoria y que se incrementa con la entrada en vigencia del requisito de pasaporte. Así, El Universo del domingo 19 de agosto describe, en la página seis, la reacciones de los migrantes ante la segunda medida: "En primer día de medida que exige pasaporte a venezolanos: Lágrimas, frustración y dolor en Rumichaca por no poder entrar".

Aun cuando la gama de sentimientos pudo incluir indignación y hasta cólera contra el gobierno ecuatoriano (el anuncio del requisito fue realizado unas cuantas horas antes de su vigencia) el énfasis radica en el dolor y la súplica que se 
refuerza con el subtítulo de la misma página: "Migrantes pidieron a gobierno permita pasar a quienes andan con niños enfermos".

La exigencia de pasaporte fue una decisión contraria a la Constitución del Ecuador, que en su Artículo 40 reconoce a todas las personas el derecho a migrar sin considerar como ilegal a nadie por esta condición y a la Ley Orgánica de Movilidad Humana. Así lo hicieron saber organismos como la Defensoría Pública y al Defensoría del Pueblo, una vez que se efectuó el anuncio.

Sin embargo, la edición de El Universo del 17 de agosto no recogía dicha contradicción y titulaba en primera plana: "Sin portar pasaporte venezolano no entrarán”. Cuando se analizan los titulares de prensa se debe tomar en cuenta el valor semántico y pragmático que envuelve al tema de la noticia y el lugar en el que se le enmarca (van Dijk, 1990). En este caso, tanto por lo escueto (el texto carece de antetítulo), como por la negación y la conjugación verbal utilizadas, si se acepta la definición de Austin (1962) de acto ilocucionario del habla (actos efectuados diciendo algo) lo que hace este titular es prohibir el ingreso de los migrantes.

Este significado se refuerza en el lead de esta noticia, cuya primera frase se construye con una metonimia con la que se evita la referencia a los funcionarios del gobierno y al propio presidente Lenín Moreno, en última instancia, responsable, como jefe de Estado, de la exigencia del pasaporte. Señala: "Desde mañana Ecuador exigirá la presentación del pasaporte a todo venezolano para ingresar al país".

El todo (Ecuador) por la parte (el gobierno) apela a un sentido nacionalista excluyente (Alsina y Gaya 2001), atribuye consenso nacional a las decisiones del régimen y deja fuera de este supuesto acuerdo a quienes están en contra de tal decisión, principalmente a los organismos de Derechos Humanos.

Así, las voces gubernamentales tuvieron un espacio privilegiado en el relato sobre la migración venezolana. En la página siete de El Universo del 17 de agosto se lee como título y subtítulo: "Pasaporte requisito para entrada de venezolanos. Según Cancillería ecuatoriana medida se adopta para garantizar la seguridad", y en un recuadro que acompaña al titular se puede leer un largo enunciado que señala: "Hay la afluencia de cerca de 250 mil venezolanos en Ecuador, informó el presidente Lenín Moreno. Días atrás, el ministro del Interior, Mauro Toscanini, informó que el 15\% de estos se queda en el país y el resto va a Perú y Chile. Regularización: Moreno dijo que la intención será la regularización y que su gobierno respeta los derechos humanos”.

El texto muestra cómo los pronunciamientos gubernamentales, lejos de ser puestos bajo sospecha, tal como corresponde al ejercicio periodístico, se respaldan con las cifras que proporcionan estas mismas fuentes, datos a los que se les otorga un carácter factual, función que cumple el citado recuadro.

Este tratamiento preferencial a las declaraciones de funcionarios públicos también lo brindó El Comercio, que tituló en la primera plana y en la misma fecha: "Venezolanos entrarán solo con el pasaporte. El ministerio de Interior informó que, desde mañana, los venezolanos que ingresen al país deben presentar su pasaporte. La cédula no es un documento confiable, según la Cancillería. En la página dos este periódico también destaca la siguiente afirmación: "25o mil venezo- 
lanos hay en el Ecuador, según los registros de los últimos cuatros años que tiene la Cancillería".

Antetítulo, título y subtítulo sintetizan los temas más importantes para un periódico, jerarquizan el discurso, recuperan núcleos de significación con función mnemotécnica y orientan las maneras de acceder a los acontecimientos representados (Pardo, 2012). Para ambos periódicos, ni las previsibles consecuencias humanitarias, ni la inconstitucionalidad de la medida, ni el hecho de que el anuncio se hizo pocas horas antes de que entrara en vigencia, lo que no daba tiempo de preparación a los migrantes, que se realizó a pocos minutos de que el presidente Lenín Moreno sostuviera una reunión con algunos migrantes venezolanos, hecho que provocó desconcierto en los propios periodistas asistentes al acto, merecían considerarse como temas centrales y, en consecuencia, convertirse en titulares en esa fecha.

En El Comercio, las voces contrarias a tal medida tuvieron eco en portada un día después, pero fueron atenuadas mediante la yuxtaposición de una idea contraria. Analicemos este recurso pragmático muy usual en el periodismo para expresar, mediante sobreentendidos, aquello que no se quiere afirmar directamente: el 18 de agosto dicho medio tituló: "La exigencia de pasaporte rige desde hoy; hay debate". En el subtítulo destaca: "La Defensoría del Pueblo y la Defensoría Pública pidieron medidas cautelares frente a la decisión del gobierno. Perú también exigirá pasaporte a venezolanos desde el 25 de agosto".
Esta última proposición, que también se encuentra en el editorial del 19 de agosto del mismo diario El Comercio: "Pasaportes y Polémica la masiva llegada de venezolanos llevó a exigir pasaporte; Perú también lo hará. Una medida debatida", conduce al lector a conjeturar que, aun cuando hay reclamos, la medida es correcta en tanto hay otros países de la misma región que exigirán igual requisito.

La interpretación de este texto no puede mirarse como subjetiva ya que "aquello que él lanza como conjetura será descodificado inevitablemente por el receptor con lo cual el autor incurre en responsabilidad: difundió un mensaje que se iba a interpretar en un sentido que él no había confirmado" (Grijelmo, 2015 p.231). Siguiendo a este mismo autor, podemos señalar además que tal yuxtaposición acarrea manipulación (omisión de datos conocidos) al silenciar el hecho de que, a diferencia de los dos países, el gobierno de Colombia no pidió pasaporte a los venezolanos y que, además, cuestionó la medida anunciada por Ecuador, suceso tan noticiable como el de la exigencia de pasaporte por parte del Perú.

El Comercio utiliza nuevamente la yuxtaposición de ideas en el titular del 13 de agosto, que relaciona la migración de venezolanos con el aumento del comercio ambulante de la ciudad de Quito, el tráfico o la contaminación ${ }^{2}$. El 13 de agosto El Comercio tituló: "En las calles de Quito hay 300 mil vendedores autónomos. El 10\% de vendedores informales en el espacio público es venezolano. El municipio decretó ayer emergencia por la crisis humanitaria”.

2 El propio periódico así lo revela cuando escribe en uno de sus recuadros: "3.840 inspecciones y operativos de comercio informal realizó la AM, de enero a junio de este año”. La palabra operativo es un término policial utilizado para referirse a las acciones de los uniformados para actividades de control delincuencial y tiene un uso muy frecuente en la prensa ecuatoriana. 
Estos textos insinúan que el incremento del comercio minorista se debe sobre todo a la presencia de venezolanos y no a otras causas como la desaceleración de la economía nacional y el incremento de la pobreza y el desempleo, que aumentó en 161.689 personas, de acuerdo con datos proporcionados en julio del 2018 del Instituto Ecuatoriano de Estadísticas y Censos (INEC).

La vía libre que tuvieron las fuentes gubernamentales en este tema se pudo notar ya con la vigencia de la emergencia migratoria, tal como se observa en los titulares de El Comercio del nueve de agosto, cuya portada destaca: "3 provincias en emergencia por éxodo de venezolanos" y en el subtítulo se lee: "El gobierno decretó ayer estado de emergencia en Carchi, Pichincha y el Oro. El objetivo es prestar atención urgente a los flujos migratorios inusuales de venezolanos. Salud reforzó su atención”. En la página número dos, como antetítulo, aparece: "El gobierno decretó ayer estado de emergencia en Carchi Pichincha y el Oro por la llegada masiva de venezolanos" y como titular: "3 provincias ponen en marcha plan de atención humanitaria. Se prioriza la atención en salud".

Los titulares ponen de relieve como asunto discursivo la acción del gobierno y dan un rol secundario a los migrantes, quienes son representados como beneficiarios de la gestión gubernamental, tal como aparece en el sumario de la página dos en el que se lee: "La Cancillería promueve la coordinación interinstitucional entre las entidades públicas seccionales y la cooperación internacional para garantizar que los migrantes venezolanos tengan una atención integral durante su paso por el Ecuador".
En este caso podemos apreciar de forma íntegra la voz oficial respecto de las acciones para enfrentar la llamada crisis migratoria, ya que en toda la nota no aparecen elementos probatorios de los mecanismos que se activarán para tales coordinaciones.

El significado que el medio otorgó a los migrantes lo podemos observar en los contenidos del subtítulo "Venezolanos en Quito", de la referida página de El Comercio, en que se relata las condiciones en las que se encontraban estos viajeros que hicieron de un sector del terminal de buses del norte de Quito, ubicado en el barrio Carcelén, un refugio improvisado. El periodista se refiere en este texto a la ayuda que reciben de los nacionales y de las expectativas que tienen los recién llegados.

Esta nota se puede analizar en el plano cognitivo planteado por van Djik (1990) en tres Macro proposiciones (M) o constructos básicos de lenguaje y pensamiento:

M1: Los venezolanos que llegan a Quito se instalan en condiciones precarias en su paso a otros países.

M2: Los venezolanos reciben ayuda de los ecuatorianos.

M3: cuador es un destino atractivo para los venezolanos.

En este nivel analítico se identifica la diferenciación que en este medio se marca entre nosotros: los ecuatorianos (generosos y habitantes de un país atractivo al extranjero) frente a ellos: los venezolanos (menesterosos), polarización que se observa en las siguientes estructuras textuales:

1. Declaraciones sobre la generosidad de los ecuatorianos 
"Son entre 40 y 50 venezolanos. Dependiendo de los pasajes que donan los ecuatorianos ellos se van. Ayer (martes) salieron 50 y hoy se fueron 30" (Rubén Peña).

2. Declaraciones sobre el anhelo de quedarse en el Ecuador:

"Mi objetivo es quedarme en el Ecuador. Yo era sargento segundo en el ejército de mi país. Nunca estuve de acuerdo con lo que hizo el gobierno. Necesito ayuda" (Rubén Peña)

"A Perú están llegando demasiados venezolanos. No puedo perder el tiempo allá, mi futuro está en Ecuador" (Wolfgang Medina)

3. Apreciación del periodista sobre el comportamiento de sus connacionales:

"Ellos agradecieron a los ecuatorianos que llegaron con ayuda, les llevaban frazadas, ropa, zapatos y juguetes. Un camión repartió alimentos".

Estos elementos suponen la presencia de un marco ideológico dentro del cual se relata la migración, que consiste, siguiendo el modelo de análisis de van Dijk (1996), en:

a) Intensificar la representación positiva sobre nosotros.

b) Intensificar la información negativa sobre ellos.

c) Mitigar la información positiva sobre ellos y

d) Mitigar la información negativa sobre nosotros.

En este mismo cuadro ideológico se ubica el editorial del 14 de agosto del citado medio titulado: "Acogida humanita- ria. La acción del estado se agradece, pero cabe coordinar políticas integrales incluyendo la seguridad", que destaca la gestión del gobierno nacional y del Municipio de Quito, así como la generosidad de la gente que se hace presente con comida y ropa. Este mismo editorial agrega: "Es una cara de la crisis. En la otra la xenofobia, el rechazo y hasta el abuso ya muestran sus colmillos. Personas que ofrecen sus mercaderías para que los viajeros las vendan en situación precaria en las calles - ya se ven las aceras y calzadas saturadas- trata de personas, hasta droga y prostitución".

$\mathrm{Si}$ bien se reconoce la xenofobia local y la explotación hacia los venezolanos como aspecto negativo del nosotros, se termina relacionando a los migrantes con los problemas sociales en los que se verían involucrados, seguramente por sus condiciones económicas lamentables, las enfermedades con las que vienen, el hacinamiento en el viven, características que no son inherentes al migrante sino que son resaltadas por quienes se refieren a ellos mediante un "proceso de constitución de una determina figura social que tiene un alcance sociopolítico y cognitivo" (Retis, 2004, p.125).

Tal como señala esta misma autora, en su elaboración discursiva la prensa atribuye a los migrantes los mismos significados que les otorgan a los países de los cuales provienen y Venezuela no ha sido un modelo de democracia para los medios de comunicación ecuatorianos. Este proceso de transferencia de significado se puede apreciar tanto en la información como en los editoriales. El sábado 18 de agosto junto a la noticia de rigor sobre la situación migratoria titulada "Venezolanos entraron con prisa este jueves y viernes” El Uni- 
verso describe una de las medidas económicas de ese país mediante el texto "Nervios por nuevos bolívares".

Así los migrantes son enmarcados, framing (Chihu, 2010), por el sentido que la prensa le atribuye a las acciones del gobierno venezolano. Un ejemplo de estos se encuentra en la página tres de El Universo del 21 de agosto: "Crisis económica por hiperinflación. En medio de tensión empezaron a circular nuevos billetes. Empresarios alertan riesgos de quiebra; protestas en el país. Analistas dicen que ni el propio Maduro podrá pagar a los burócratas con las nuevas medidas. Familias no saben cuál será su destino. En recuadro: "6 medidas polémicas".

Todas estas noticias, ubicadas en el mismo lugar que las referencias al tema migratorio venezolano, cumplen una de las funciones del framing: "atribuir la responsabilidad o la culpa por una situación injusta a una intuición o actor reconocible (atribución diagnóstica)" (p.25). La parte relacionada con las soluciones y acciones específicas (atribución pronóstica) la cumplen editoriales como el de El Comercio del 23 de agosto en el cual se señala: Las iniciativas regionales y aún la convocatoria "técnica" incluye a representantes del gobierno chavista de Nicolás Maduro, lo cual puede ser un obstáculo a posibles salidas. Es difícil que ese gobierno se reconozca como el causante de la grave crisis interna y sus consecuencias humanitarias a nivel regional. Pero el problema es más lacerante y amerita una salida urgente.

Así, la línea general de acción a la que se refiere para evitar la migración venezolana es la salida del presidente Nicolás Maduro mediante una acción que comprometa a los países de la región.

\section{Consideraciones finales}

El relato sobre la migración venezolana elaborado por los diarios El Comercio y El Universo, durante los primeros días de la denominada "emergencia migratoria”, se caracterizó por la representación de estos ciudadanos como sujetos problemáticos de recepción y al mismo tiempo como personas dignas de lástima y piedad por parte de los lectores. En este discurso las fuentes gubernamentales tuvieron un tratamiento privilegiado ya que sus pronunciamientos no fueron contrastados oportunamente e incluso se los respaldó, de manera particular, cuando las autoridades decretaron medidas para impedir que los venezolanos pudieran ingresar al Ecuador.

La postura de los periódicos analizados muestra que la idea de que la noticia es una ventana con cristales transparentes, por la cual se puede mirar el mundo, es ya poco defendible debido a que no se consideran los elementos que empañan los cristales, tal es el caso de los estereotipos que se construyen sobre el otro, que actúan como barreras para la comprensión de la realidad ajena y de la propia. La simplificación y la emotividad puede ser un buen recurso para construir y vender noticias, pero no ayudan a explicar fenómenos tan complejos como el de la migración.

No se trata de pedir a los medios aquello que no están en capacidad de brindar, ni de cargar sobre sus espaldas toda la responsabilidad en torno a la xenofobia y discriminación, sino de animar una discusión que procure mejorar sus prácticas informativas, de tal manera que sus relatos contribuyan a desterrar estas formas de violencia en vez de reproducirlas. 


\section{Bibliografía}

Austin, J. (2001). Cómo hacer cosas con las palabras. Barcelona. Editorial PAIDOS.

Cruz, P. (2009). "Comunicación y Migración: Análisis de un proceso de interactividad en los periódicos on line del Ecuador". Tesis de maestría, FLACSO. En: http://repositorio.flacsoandes.edu.ec/xmlui/handle/10469/1966

Cerbino, M.; Benalcázar G.; Pérez, 0. (2006). "Observatorio de Análisis del discurso de medios de comunicación sobre emigración". Quito. FLACSO, Plan Migración, Comunicación y Desarrollo. En: https://www.flacso.edu.ec/portal/pnTemp/PageMaster/lyj0y9ze7xdagdxqrw7pp5y3clpkfm.pdf Constitución de la República del Ecuador (2008). En: https://www.oas.org/juridico/mla/sp/ecu/sp_ecu-int-text-const.pdf

Checa, F. (2008). "Imágenes e imaginarios sobre la migración en la prensa ecuatoriana y española". En ALER. Investigación "Prensa y migración en Ecuador y España" Informe final. Disponible en: https://www.researchgate.net/publication/267954207_Imagenes_e_imaginarios_sobre_la_migracion_en_la_prensa_ecuatoriana_y_espanola

Chihu, A. (2010). El framing del spot publicitario. México D.F. Universidad Autónoma Metropolitana

Dader, J. ( 2008). "Secuestro y fuga de la opinión pública ante el periodismo. Reflexiones del papel del periodismo actual en la construcción de lo público". En Capellán, C. Opinión Pública. Historia y Presente. (pp.227-245) Madrid. Ed. Trotta

Espeche, E. (2010). "La dimensión filosófica de la praxis informativa objetividad y Parcialidad". En Cimadevilla G. y Fagundes, D. (Coord.) La comunicación en tiempos de crisis, Il coloquio Argentina-Brasil de ciencias de la comunicación (pp.203-225). Río Cuarto. Argentina. Editorial Universidad Nacional de Río Cuarto.

Fairclough, N y Wodan, R. (1997). "Análisis Crítico del Discurso". En van Dijk, T. El discurso como Interacción social. Estudios sobre el discurso II. Una introducción multidisciplinaria. (pp. 331- 367). Barcelona. Gedisa

Flor, M. (2015). "Migración cubana en el Ecuador: Una mirada al proceso de descalificación". FLACSO. En: http://repositorio.flacsoandes.edu.ec/handle/10469/9542

Grijelmo, Á. (2012). La información del silencio. Cómo se miente contando hechos verdaderos. Madrid, España: Editorial Taurus.

Graton, B. (2005). "Ecuador en la historia de la migración internacional. ¿Modelo o aberración?" En: Herrera, G.; Carrillo, M y Torres, A. (Edit.). La migración ecuatoriana transnacionalismo, redes e identidades (pp.31-57). Quito- FLACSO. En:http://www.flacsoandes.edu.ec/libros/digital/45825.pdf

Muñoz, L, y Piñero, E. (2014). "La amenaza de la migración: cubanos en el Ecuador". En: http://revista.sangregorio.edu.ec/index.php/REVISTASANGREGORIO/article/view/143

Ortega y Ospina (2012). "No se puede ser refugiado toda la vida: Refugiados Urbanos: El caso de la población colombiana en Quito y Guayaquil". Quito. FLACSO. En: http://www.flacsoandes.edu.ec/libros/127467-opac

Pardo, G. (2013). Cómo hacer análisis crítico del discurso. Una perspectiva Latinoamericana. Bogotá. Universidad Nacional de Colombia. En: http://www.bdigital.unal.edu.co/10250/1/C\%C3\%B3mo\%20hacer\%20ACD.pdf

Retis, J. (2004). La imagen del otro: Inmigrantes latinoamericanos en la prensa española. Sphera Pública (4). pp. 119139. En: https://www.redalyc.org/html/297/29700408/ 
Rodrigo, Iván (2016). "Credibilidad de medios y periodistas en Ecuador en el año 2015". Razón y Palabra 20 (95)., pp. 659- 678. En: https://www.redalyc.org/pdf/1995/199550145040.pdf

Santander, P (2011). "Por qué y cómo hacer Análisis de Discurso". Cinta moebio 41: 207-224 En: www.moebio.uchile.cl/41/santander.html

Shussler, S. (2009). "Entre la sospecha y la ciudadanía: refugiados colombianos en Quito". Quito. FLACSO. En: http://www.flacsoandes.edu.ec/libros/digital/42691.pdf

Van Dijk (2003). "La multidisciplinaridad del análisis crítico del discurso: un alegato en favor de la diversidad". En Ruth Wodak \& Michael Meyer, Métodos de análisis crítico del discurso. Barcelona: Gedisa, 2003., pp. 143-177. En: http://www.discursos.org/oldarticles/La\%20multidisciplinariedad.pdf

-------- (1997). El discurso como Interacción social. Estudios sobre el discurso II. Una introducción multidisciplinaria. Barcelona. Gedisa

-------(1996). "Opiniones e Ideología en la Prensa Voces y culturas", (10, II Semestre 1996), pp. 9-50. En: http://www.discursos.org/oldarticles/0piniones\%20e\%20ideolog\%EDas\%20en\%20la\%20prensa.pdf

El Comercio (8 de agosto del 2018). "Emergencia en Carchi, Pichincha y El Oro por crisis humanitaria de ciudadanos venezolanos en Ecuador". En: https://www.elcomercio.com/actualidad/ecuador-emergencia-venezolanos-pichincha-eloro.html

(19 de agosto del 2018). "Mauro Toscanini: para nosotros es legal y legítimo pedir pasaporte". En: https://www.elcomercio.com/actualidad/maurotoscanini-entrevista-pasaporte-migrantes-venezolanos.html El Nacional (7 de septiembre del 2017) "Venezolana tilda de indios y feos a ecuatorianos y desata debate migratorio". En: http://www.el-nacional.com/noticias/latinoamerica/venezolana-tilda-indios-feos-ecuatorianos-desatadebate-migratorio_203887

INFOBAE (5 de mayo del 2018) "Así fue el asesinato de un taxista a puñaladas que conmociona a Ecuador". En: https://www.infobae.com/america/america-latina/2018/05/05/asi-fue-el-atroz-asesinato-de-un-taxista-a-punaladas-que-conmociona-a-ecuador/ La Hora (9 de mayo del 2018). Xenofobia crece en Ambato) En: https://lahora.com.ec/tungurahua/noticia/1102155496/xenofobia-crece-en-ambato

El Universo (28 de julio de 2017). "Unos 2.000 venezolanos ingresan cada día a Ecuador, dice jefa de Migración en Carchi". En https://www.eluniverso.com/noticias/2017/07/28/nota/6302236/cientos-venezolanos-hacen-fila-frontera-norte-ingresar-ecuador 